\title{
Development of New Indicators for the Launch of Japan Agency for Medical Research and Development (AMED)-Trend Analysis for US NIH Funding
}

\author{
Mari Jibu ${ }^{1}$, Yoshiyuki Osabe ${ }^{2, *}$ \\ ${ }^{1}$ Policy-Oriented Research Group, National Institute of Science and Technology Policy (NISTEP), Tokyo, Japan \\ ${ }^{2}$ Patent Information Policy Planning Office, Japan Patent Office (JPO), Tokyo, Japan
}

\section{Email address:}

mari.jibu@nistep.go.jp (M. Jibu), osabe-yoshiyuki@jpo.go.jp (Y. Osabe)

${ }^{*}$ Corresponding author

\section{To cite this article:}

Mari Jibu, Yoshiyuki Osabe. Development of New Indicators for the Launch of Japan Agency for Medical Research and Development (AMED)-Trend Analysis for US NIH Funding. American Journal of Information Science and Technology. Vol. 2, No. 3, 2018 , pp. 64-73. doi: 10.11648/j.ajist.20180203.11

Received: September 10, 2018; Accepted: October 6, 2018; Published: October 27, 2018

\begin{abstract}
For the sake of providing evidences that contribute to policy making or strategy planning in AMED (a Japanese version of the $\mathrm{NIH}$ ) and pharmaceutical companies, this study tried to analyze a current state of the pharmaceutical industry based on new indicators and forecast the future thorough a series of papers. In this article, this study tried to give an overview of the funding trends for the drug development o this study analyzed 18,845 contracts between licensors and partners whose headquarters are located in the U.S. As a result, Major companies, SMEs are dealing not only with other SMEs but also dealing actively with government agencies and foundations in U.S. Government involvement is one of the most important aspects, because it provides innovation system structure to link each entity. The foundation also plays the important role as a funding partner in U.S. Focusing the role of SMEs in U.S., there are some transactions that SMEs buy the candidates of major companies on the discovery phase. On the other hands, investment from venture capital firms in Japan is one tenth of that in US. In AMED, introductory service of venture capital, commercialization, and government procurement will become useful systems.
\end{abstract}

Keywords: AMED, NIH, Pharmaceuticals, R\&D, EBPM, Funding, SBIR, Venture Capital

\section{Introduction}

Diverse studies have been conducted to study the origin, trajectory, and destination of knowledge flows and the delays in the science and technology system. Patents and citations between patents and to non-patent literature (NPL) are analysed to understand knowledge spillovers [1] or to measure patent quality [2]. The OECD Science, Technology and Industry Scoreboard 2013 [3] uses comprehensive and up-to-date data to report on knowledge flows via collaboration networks (e.g., derived from co-authored publications and co-inventors on patents), international migration of researchers (e.g., estimated from changes in author's addresses on publications), but also flows of royalty and license fees for technologies. Pharmaceutical innovation is particularly important for drug discovery, as research and development $(\mathrm{R} \& \mathrm{D})$ costs are huge and major challenges exist for arriving at cost-effective new drugs. In fact, there is a steady decrease in $\mathrm{R} \& \mathrm{D}$ productivity over the last number of years [4].

The main purpose of this study is to provide evidence in order to contribute to evidence-based-policy-making (EBPM) and strategic planning. Especially for the sake of providing evidence for AMED (see Note below) and pharmaceutical companies, the authors tried to analyze a current state of the pharmaceutical industry based on new indicators and forecast the future, thorough a series of papers below. This is the English translation of seventh paper of the authors' consequence papers on scientometric analysis in the pharmaceutical field.

In the authors' consequential papers, "Development of new indicators for the launch of a Japanese version of the NIH (1) - (3)" showed that the analysis of pipelines of drug development by each pharmaceutical company can deeply 
measure the R\&D capacity of each country in the current stage and in future [5, 6]. In order to facilitate open innovation in a multi-step R\&D process, the 3rd paper showed that it was important for so-to-speak "roundabout of drug discovery" centered on SMEs and start-ups [7].

In addition, the other papers showed that the authors original indicator "Purified Patent Family Number" calculated by parameters such as International Patent Classifications (IPC) number, cited patent number, and non-patent literature (NPL) number cited by patents is a crucial indicator for predicting the basic research potential of the pharmaceutical industry in each country $[8,9]$.

Furthermore, in another paper, the authors analyzed drug R\&D situation by disease type [10]. The paper showed that cancer, infection and nervous system disease are current hot issue of R\&D. It also showed that SMEs play a central role in R\&D in US and UK, whereas major companies play a central role in R\&D in Japan.

The authors also analyzed the knowledge flows of the pharmaceutical innovation system, focusing on the patents related with pipelines and drugs. It is shown that the patents/NPLs cited on the patents by patent examiners/applicants as well as the technical fields of cited patents are key factors in order to see the knowledge flows [11].

This article is the seventh paper of these consequential papers. The authors tried to grasp US trends of pharmaceutical funding system such as government agencies and private foundations for grants. Please note that this article is a personal opinion of the authors, and not expressing opinions of the organization that the authors belong to.

\section{Database}

In this analysis, the authors used Thomson Reuters' Cortellis for Competitive Intelligence database (hereafter "Cortellis database"). This database includes approximately 50,000 drugs and pipelines information, and 35,000 contract information between organizations. It can be a platform bringing together the industry's most comprehensive deals analysis coverage. Now this database is found as Cortellis Deals Intelligence.

The data extraction date is December 11, 2013.

Among 35,000 organization-to-organization contract information, the authors analyzed 18,845 contracts between licensors and partners whose headquarters are located in the U.S. This data could be analyzed in order to identify potential deal partners by therapeutic area, mechanism, technology, and stage of development.

\section{Results}

\subsection{Contract Between Organizations}

Figure 1 shows a detailed breakdown of contracts between organizations in order of the number of cases. Table 1 indicates a content of the contract shown in Figure 1.

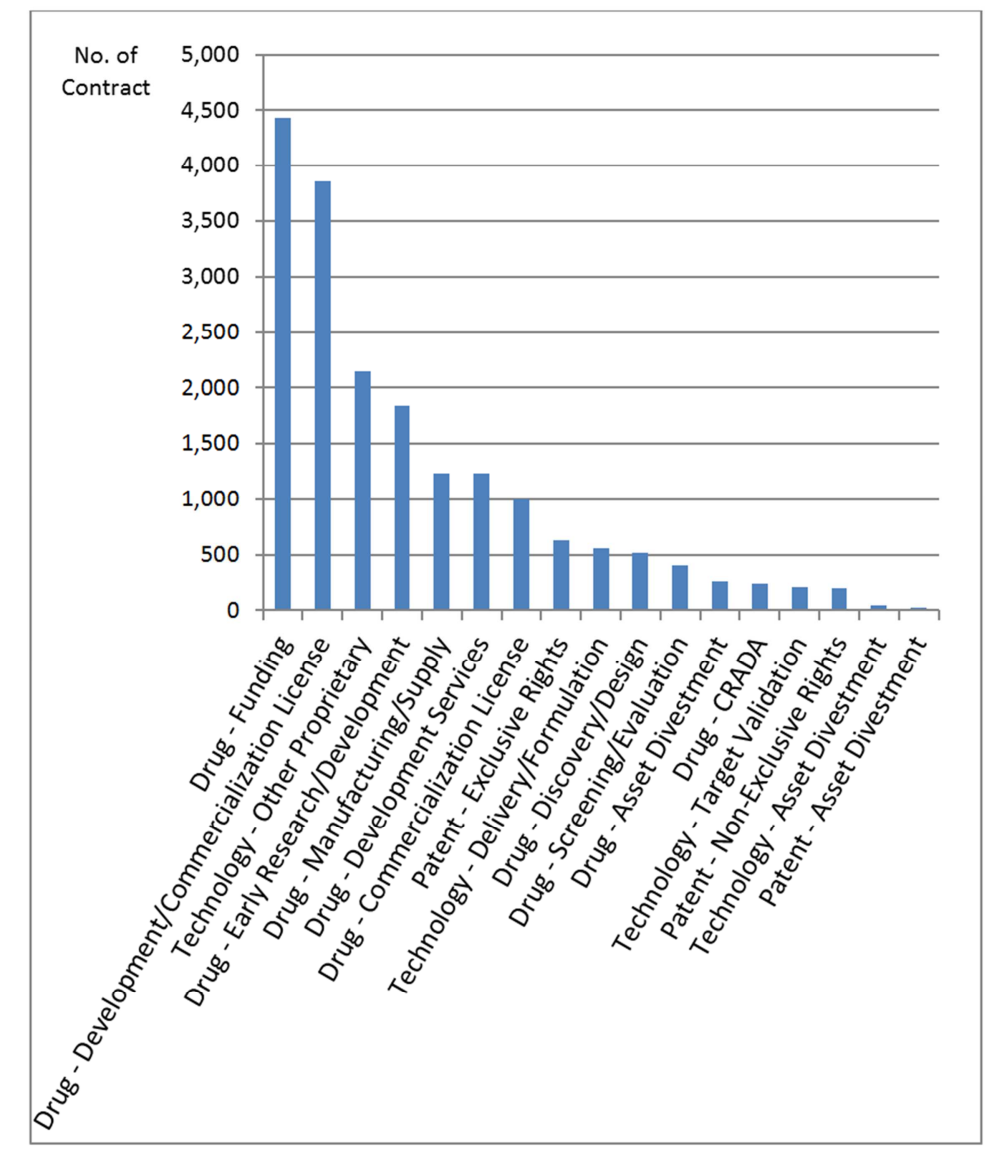

Figure 1. Detail of Contracts. 
Table 1. Definition of contracts.

\begin{tabular}{|c|c|}
\hline Drug-Asset Divestment & A licensor sells all assets related to pharmaceuticals to a partner. \\
\hline Drug-Commercialization License & $\begin{array}{l}\text { A partner agrees to acquire licenses to sell drugs from a licensor or to promote selling drugs in cooperate with the } \\
\text { licensor. }\end{array}$ \\
\hline Drug-CRADA & A company and an government agency sign CRADA (collaborative research and development contract). \\
\hline $\begin{array}{l}\text { Drug-Development/Commercialization } \\
\text { License }\end{array}$ & A partner acquires license to develop drugs from a licensor and commercialize (sell) them. \\
\hline Drug-Development Services & A service company agrees to provide drug development services to a partner. \\
\hline Drug-Discovery/Design & $\begin{array}{l}\text { A licensor and a partner agree to jointly or individually develop business strategies for drug development and to } \\
\text { discover and design drug candidate compounds. }\end{array}$ \\
\hline Drug-Early Research/Development & $\begin{array}{l}\text { A licensor and a partner sign an alliance to jointly use expertise and resources in order to develop drug candidate } \\
\text { compounds. }\end{array}$ \\
\hline Drug-Funding & Receive funds for drug development. \\
\hline Drug-Manufacturing/Supply & A licensor agrees to manufacture and supply drugs to a partner. \\
\hline Drug-Screening/Evaluation & $\begin{array}{l}\text { A licensor agrees to screen or evaluate drug candidate compounds to potential targets and certain models for a } \\
\text { partner. }\end{array}$ \\
\hline Paten-Asset Divestment & A licensor sells all patent assets to partner. \\
\hline Patent-Exclusive Rights & A partner acquires exclusive license to use patents belonging to a licensor. \\
\hline Patent-Non-Exclusive Rights & A partner acquires non-exclusive license to use patents belonging to a licensor. \\
\hline Technology-Asset Divestment & A licensor sells all assets related to his technology to a partner. \\
\hline Technology-Delivery/Formulation & $\begin{array}{l}\text { A partner acquires license for drug delivery and drug formulation technology from a licensor, or a licensor } \\
\text { cooperates with partner in manufacturing drugs. }\end{array}$ \\
\hline Technology-Other Proprietary & A partner uses licensor's technology or acquires license to use it with a licensor. \\
\hline Technology-Target Validation & $\begin{array}{l}\text { A partner acquires a license to use licensor's technology to evaluate and verify the estimated target of the } \\
\text { developed drug. }\end{array}$ \\
\hline
\end{tabular}

The largest number of contracts between the two organizations was Drug-Funding (fund for drug development), 4,436 cases. It is followed by Drug-Development/Commercialization License, Technology-Other Proprietary. In the analysis of the paper [7], "Evaluate Pharma database" by Evaluate Ltd. was used, and contracts between two organizations was analyzed, but the database did not include data of Drug-Funding.
The database used this time, "Cortellis database", includes Drug-Funding (funds for drug development). Figure 2 shows which partner signs a contract with what kind of licensor organization. Organizations are classified into 8 categories, which are Major company, SMEs, Pharma-related-company, Generic company, Funds, University, Government, and Others. Table 2 shows the definition of each category.

Table 2. Definition of business entities.

\begin{tabular}{|c|c|}
\hline Business Entitiy & Explanation \\
\hline \multirow[t]{3}{*}{ Major } & $\begin{array}{l}\text { A major company that develops and sells new drugs. This category includes a major company that also develops non-active } \\
\text { ingredients and a major company that also manufactures and sells generic drugs in addition to new drugs. }\end{array}$ \\
\hline & A company below; \\
\hline & A company that develops new drugs and does not belong to a major company. \\
\hline SME & $\begin{array}{l}\text { This category includes a SME or start-up that also develops non-active ingredients and a SME or start-up that also manufactures } \\
\text { and sells generic drugs in addition to the development of new drugs. } \\
\text { A company that has been adopted in the United States' SBIR (Small Business Innovation Research) program between } 1983 \text { and } \\
2011 \text {. }\end{array}$ \\
\hline Generic & $\begin{array}{l}\text { A company that manufactures and sells generic drugs, not new drugs. This category includes a company that also develops } \\
\text { non-active ingredients and do not develop new drugs in addition to generic drugs. }\end{array}$ \\
\hline Pharma-related & $\begin{array}{l}\text { A company that develops non-active ingredients of pharmaceuticals, such as improving administration route and changing dosage } \\
\text { form. }\end{array}$ \\
\hline Funds & $\begin{array}{l}\text { A non-profit private foundation supporting development of drugs (Bill \& Melinda Gates Foundation, Michael J. Fox Parkinson } \\
\text { Disease Research Foundation, etc.) }\end{array}$ \\
\hline Unknown & A company whose business type is unknown \\
\hline
\end{tabular}




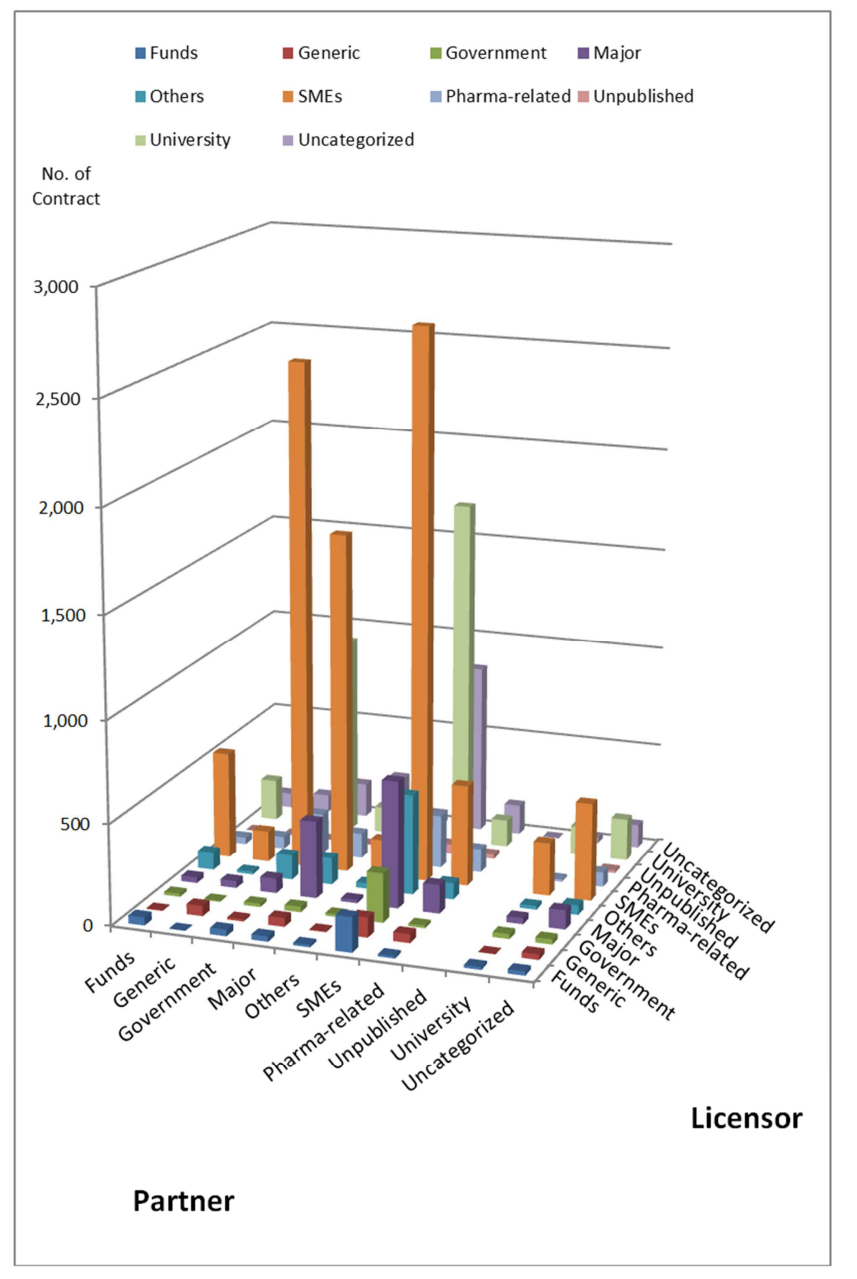

Figure 2. Contracts by Licensor Type and Partner Type.

It turns out that SMEs play a central role, as the authors reported in previous paper [7]. Not only are there large contracts between a Major company and a SME, or a SME and other SMEs, but the contract of Government or Funds are also active with SMEs. Figure 3 shows the number of contracts between partner and licensor with limitation of contracts type "Drug-Funding".

Funding related to pharmaceuticals includes many government agencies and foundations as partners. Both of them include many grants for SMEs, followed by university. It is noteworthy that the foundation plays an important role in US funding system.

Moreover, figure 4 shows in which phase government agencies and foundations made a contract. There are several phases in drug R\&D. In this study, phases are divided into "Discovery", "Phase 1", "Phase 2", "Phase 3", "Before Approval", "Approval", and "Marketed". "Discovery" includes basic research and nonclinical study (animal study). Category also includes "Unknown" or "Uncategorized" because of data source.

Figure 4 indicates that government agencies and foundations have tendency to fund to SMEs and universities holding pipelines in discovery stage. It also shows that government agencies and foundations mostly invest pipelines in basic research stage.

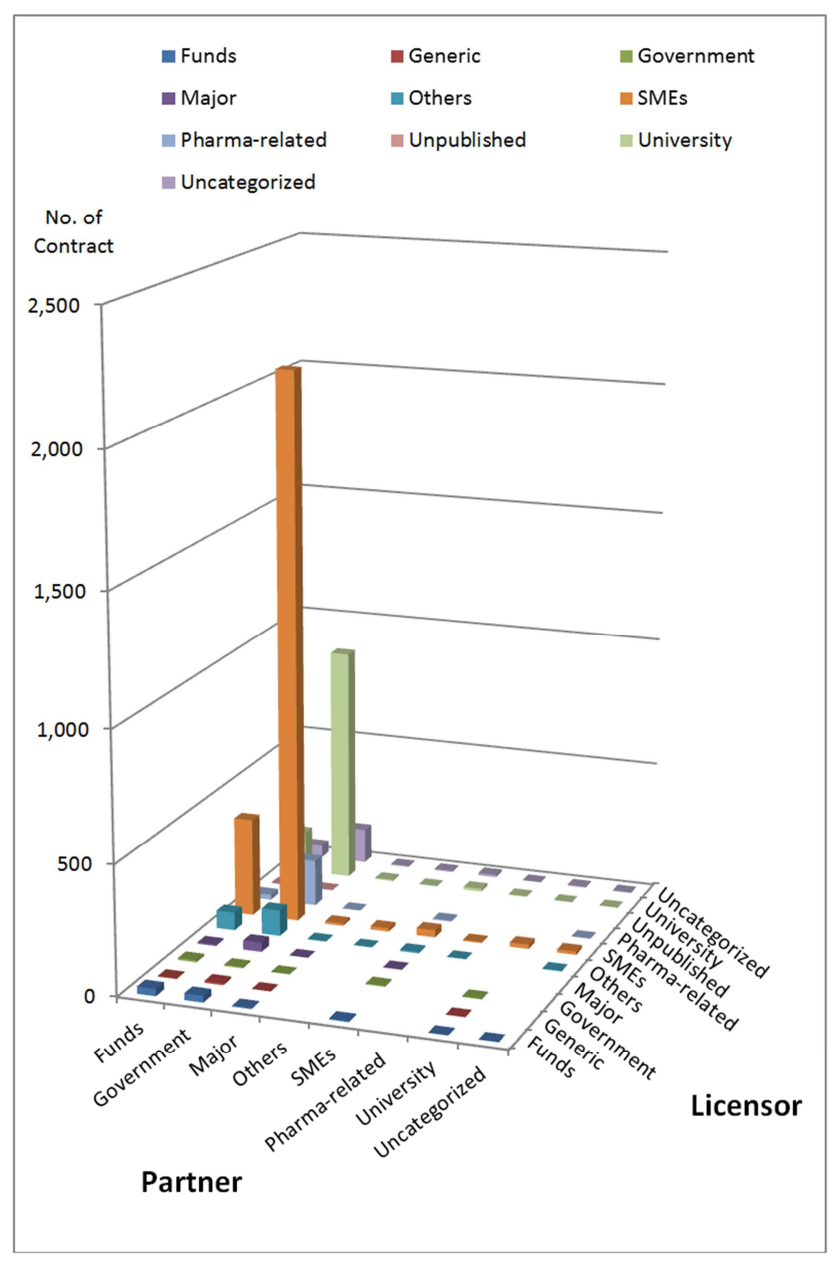

Figure 3. Contracts by Licensor Type and Partner Type in Drug-Funding.

In terms of Drug-Development/Commercialization License, as shown in Figure 5, SMEs mostly have contracts with universities holding pipelines in discovery stage. Following that, SMEs have contracts with SMEs holding pipelines in discovery stage, then Major companies have contract with SMEs holding pipelines in discovery stage. It is worth noting that SMEs have a tendency of having a contract with Major companies holding pipelines in discovery stage.

R\&D in Pharmaceutical field has high risk and it often takes a long time for clinical trials. Moreover, the burden of R\&D expenditure will be enormous [12]. Even major companies should prioritize its drug R\&D strategy among many drug candidates. It means that even major companies must select and concentrate their investment, considering their own economic environment and business environment. Some of drug candidate are difficult to develop routes into markets or to drive profitable growth because of rare diseases. These drugs may not initiate research and development. It can be considered that SMEs made contracts with major companies as partners of research and development/manufacturing Commercialization License, in terms of such a drug candidate. 


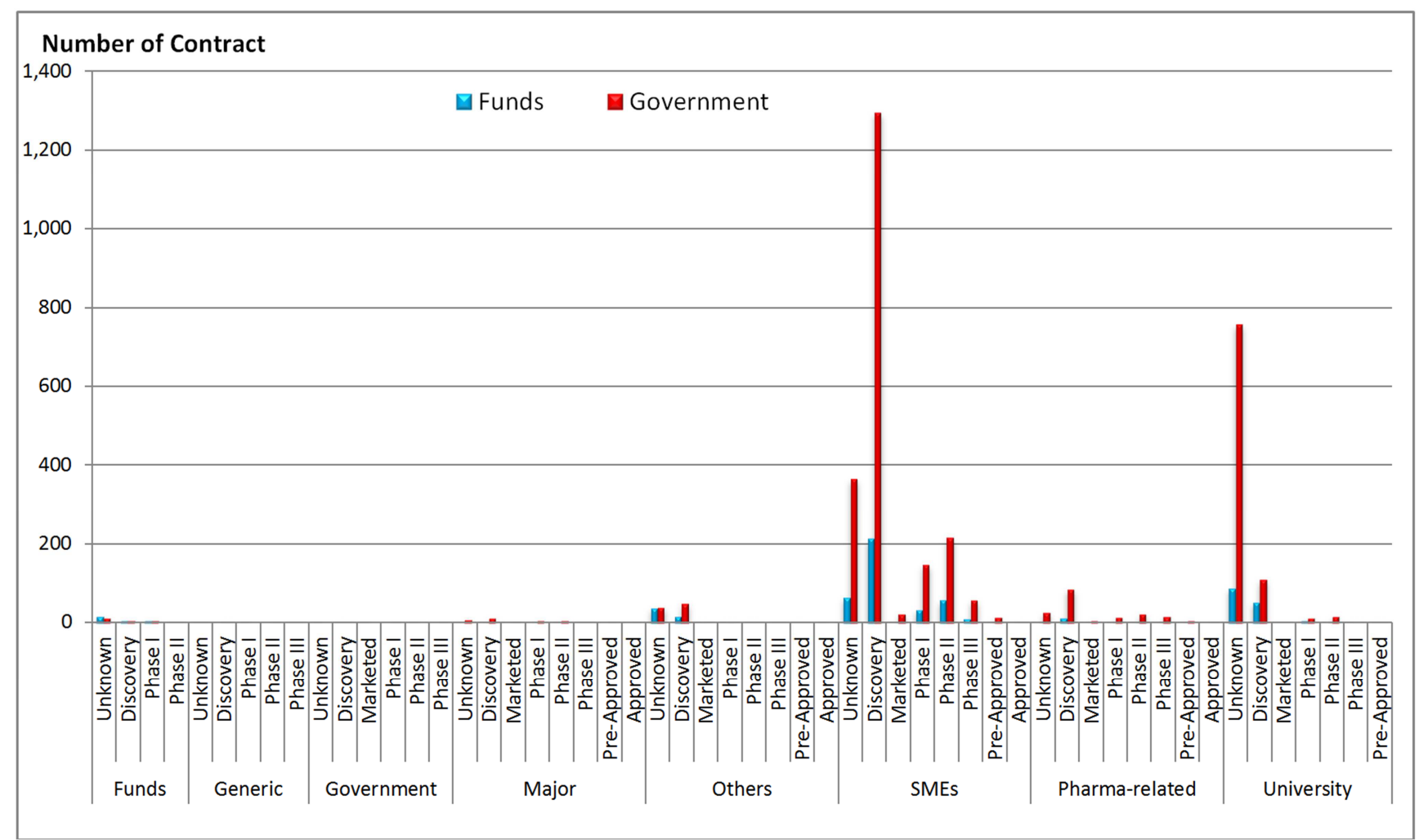

Figure 4. Number of Contracts on Drug-Funding (Funds and Government).

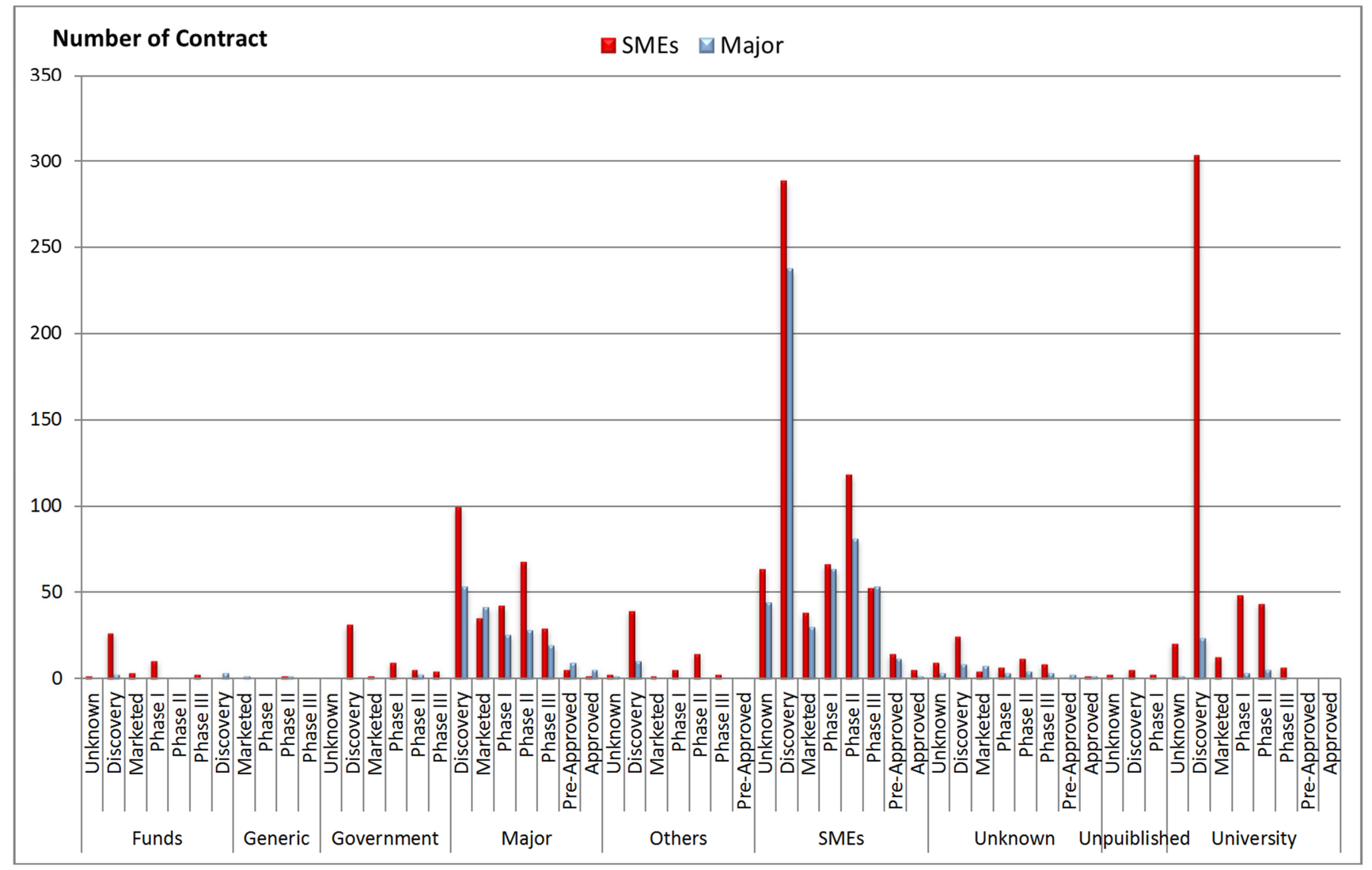

Figure 5. Number of contracts on Drug-Funding (Major and SMEs). 
Table 3 shows the top 20 partners of deals for pharmaceuticals industry in the U.S. The top three are medical research institutions under the United States Department of Health and Human Services (HHS). As shown in Figure 1, Drug-Funding accounts for approximately 23.5\% of the total $(4,436$ out of 18,845$)$, so foundations in the U.S. occupy the top. National Institutes of Health (NIH) consists of several laboratories and research centers, and all of them as a whole are referred to as NIH.

Table 3. Top 20 partners and number of contracts.

\begin{tabular}{|c|c|c|}
\hline Order & Partner Name & Number of Contracts \\
\hline 1 & National Institute of Allergy and Infectious Diseases & 703 \\
\hline 2 & National Institutes of Health & 681 \\
\hline 3 & National Cancer Institute & 637 \\
\hline 4 & Pfizer Inc & 517 \\
\hline 5 & US Government & 447 \\
\hline 6 & Merck \& Co Inc & 376 \\
\hline 8 & Eli Lilly \& Co & 199 \\
\hline 9 & Abbott Laboratories & 175 \\
\hline 10 & National Institute of Neurological Disorders and Stroke & 165 \\
\hline 11 & National Center for Research Resources & 162 \\
\hline 12 & Genentech Inc & 138 \\
\hline 13 & National Heart Lung and Blood Institute & 126 \\
\hline 14 & US Department of Defense & 110 \\
\hline 16 & The Michael J. Fox Foundation & 105 \\
\hline 17 & National Institute on Drug Abuse & 94 \\
\hline 18 & US Health and Human Services Department & 90 \\
\hline 19 & MedImmune LLC & 87 \\
\hline 19 & Bill \& Melinda Gates Foundation & 87 \\
\hline
\end{tabular}

These laboratories and research centers are divided into in-house and out-house departments by respective missions. The in-house department conducts research and clinical trials in the laboratory of the NIH in Bethesda, a suburb of Washington, D.C. Out-house departments provide grants for NIH's laboratories and research centers. In this analysis, all NIH laboratories and research centers that could not be identified are designated as NIH.

As mentioned above, one of the strengths of the United States is presence of foundations ranked as 16th and 19th. The Michael J. Fox Foundation ranked as 16th is a foundation founded in 2000 by American actor Michael J. Fox for research on Parkinson's disease. In 2013, its total funding amounted to $\$ 54,058,647$. Bill \& Melinda Gates Foundation ranked as the 19th is a foundation founded in 2000 by Gates, Microsoft. It is funding for research on HIV/AIDS, malaria infection and so on, as the Global Health Program. The Discovery \& Translational Sciences program is distinctive and has the function of bridging outstanding basic research to actual solution.

The top 10 entities in 2014 belong to all pharmaceutical-related fields except Bill \& Melinda Gates Foundation ranked as the 1st and Ford Foundation ranked as the 7th (Table 4). Among the top 10 entities, the total of 8 entities excluding $1 \mathrm{st}$ and 7 th is about 4.7 billion dollars a year [13]. According to the government draft budget of 2014, 121.5 billion yen (about 1 billion dollars, calculating 1 dollar is 100 yen) has been prepared for the creation of AMED (Japan version NIH) [14]. However, it is only a quarter of the funding amount of the top nine companies excluding the 1 st one of the U.S. entities.

Table 4. Top10 funds in U.S and their annual funding fee.

\begin{tabular}{lll}
\hline Order & Funds name & Annual Funding Fee (\$) \\
\hline 1 & $\begin{array}{l}\text { Bill \& Melinda Gates Foundation } \\
\text { (WA) }\end{array}$ & $3,239,412,884$ \\
2 & $\begin{array}{l}\text { Genentech Access To Care } \\
\text { Foundation (CA) }\end{array}$ & $665,582,721$ \\
3 & $\begin{array}{l}\text { The Abbvie Patient Assistance } \\
\text { Foundation (IL) }\end{array}$ & $646,459,794$ \\
5 & $\begin{array}{l}\text { Lilly Cares Foundation, Inc. (IN) } \\
\text { GlaxoSmithKline Patient Access }\end{array}$ & $609,678,898$ \\
6 & $\begin{array}{l}\text { Programs Foundation (PA) } \\
\text { The Bristol-Myers Squibb Patient }\end{array}$ & $549,953,667$ \\
7 & $\begin{array}{l}\text { Assistance Foundation, Inc. (NY) } \\
\text { Merck Patient Assistance Program, }\end{array}$ & $520,507,909$ \\
8 & $\begin{array}{l}\text { Inc. (NJ) } \\
\text { Pfizer Patient Assistance }\end{array}$ & $515,726,553$ \\
9 & $\begin{array}{l}\text { Foundation, Inc. (NY) } \\
\text { Sanofi Foundation for North }\end{array}$ & $497,491,467$ \\
10 & $\begin{array}{l}\text { America (NJ) } \\
\text { Johnson \& Johnson Patient }\end{array}$ & $496,523,981$ \\
\hline
\end{tabular}

Figure 6 shows the ratio of each contract detail of the above-mentioned top 20 entities. In terms of the top 8 NIH-related organizations, the major contracts are Drug-Funding. Entities from 4th to 9th are global companies (excluding the 5th, U.S. government), followed by Pfizer Inc., Merck \& Co Inc., Bristol-Myers Squibb Co, Eli Lilly \& Co, Abbott Laboratories. They do not provide grants like NIH does, but contract Drug-Development/ Commercialization 
License, which indicates that a partner acquires license to develop drugs from a licensor and commercialize (sell) them And that they support drug R\&D after commercialization license. Genentech Inc. ranked as 12th was one of the global companies as it became under umbrella of Roche in 2009.

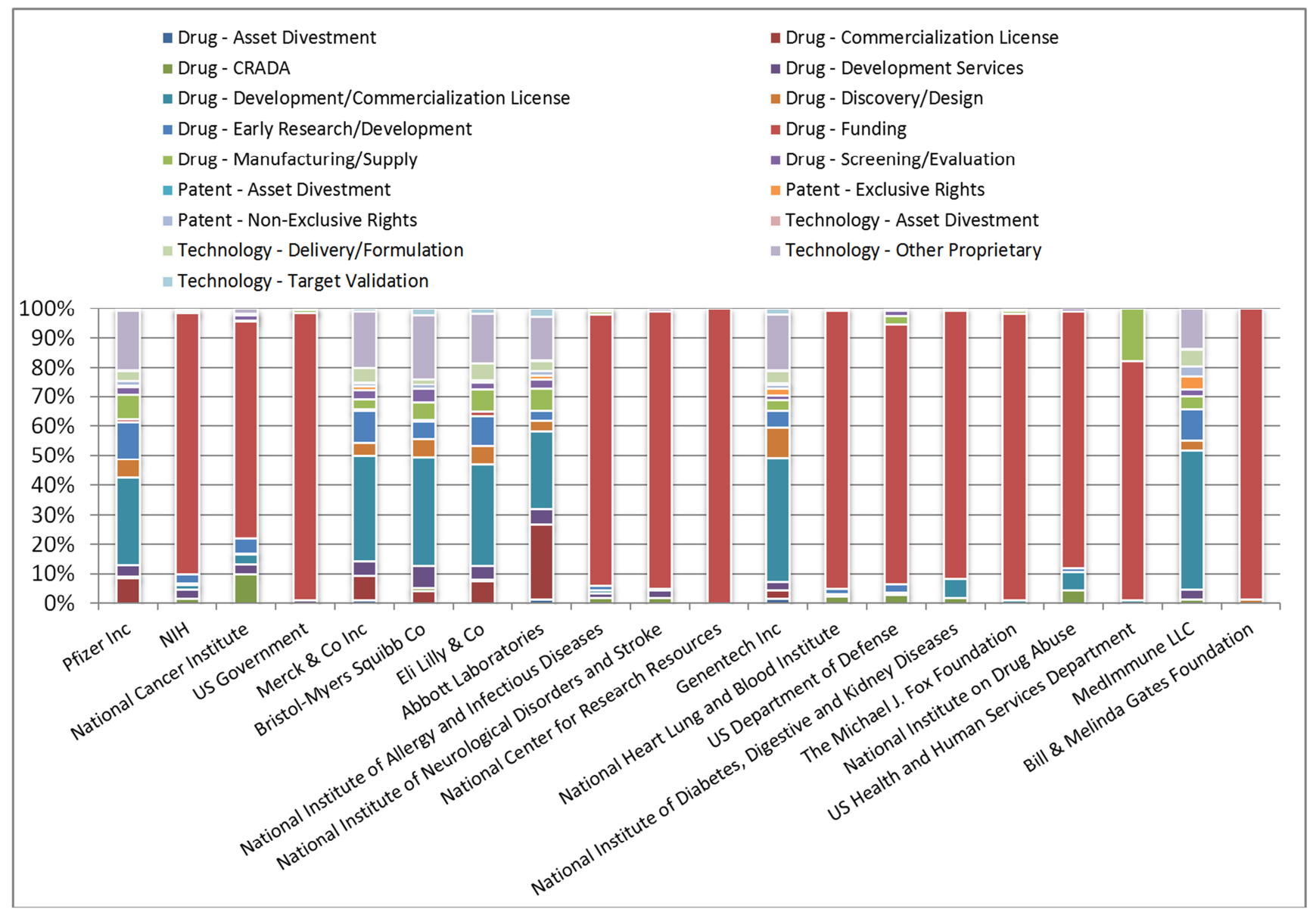

Figure 6. Contract detail of the top 20 partners.

On the other hands, figure 7 shows details of the number of top 20 licensor and deals. Except unpublished, Johns Hopkins University is ranked as 1st, National Cancer Institute as 2nd and MD Anderson Cancer Center as 3rd. Of the top 20, ten institutions include universities, and Drug/Funding is the most popular as a deal, then Drug-Development/Commercialization License.

For Scripps Research Institute and Massachusetts General Hospital, which are hospitals affiliated with universities and nonprofit organizations, Drug-Screening / Evaluation is the major for Scripps Research Institute and Massachusetts General Hospital. The former is the nonprofit organization, the latter is the hospital which is affiliated with university. Drug-Screening / Evaluation means that licensor will screen and evaluate drug candidate compounds against potential targets and certain models for partners.

\subsection{Funding for SMEs}

Small Business Innovation Research (SBIR) and Small Business Technology Transfer (STTR) are the largest grans for SMEs and start-ups in the United States. This program also occupies 628 deals out of 4,436 deals of the U.S.
Drug-Funding, which is about $14 \%$ of Cortellis database.

The SBIR program was created in 1982 in order to promote private sector innovation. Ministries with over 100 million dollars as an annual external research and development budget are obliged to contribute $2.8 \%$ of the budget to the SBIR program. Participating ministries are Ministry of Agriculture, Ministry of Commerce, Department of Defense, Department of Education, Ministry of Energy, Homeland Security Department, Ministry of Transport, Ministry of Health and Human Services, Environment Agency, Aerospace Department, and National Science Foundation. The program supports SMEs' R\&Ds, which are highly likely to be commercialized. It is divided into Phase I, Phase II, and Phase III as 3 selection steps. Phase I is given to feasibility study. It affords not to exceed 150,000 dollars for about 6 months of research period. Phase II further extends research of phase I, affording one million dollars, with a research period of approximately two years. Phase III is not foundations by the SBIR program, but it is an introduction to venture capital for commercialization and government procurement for the U.S. government. 


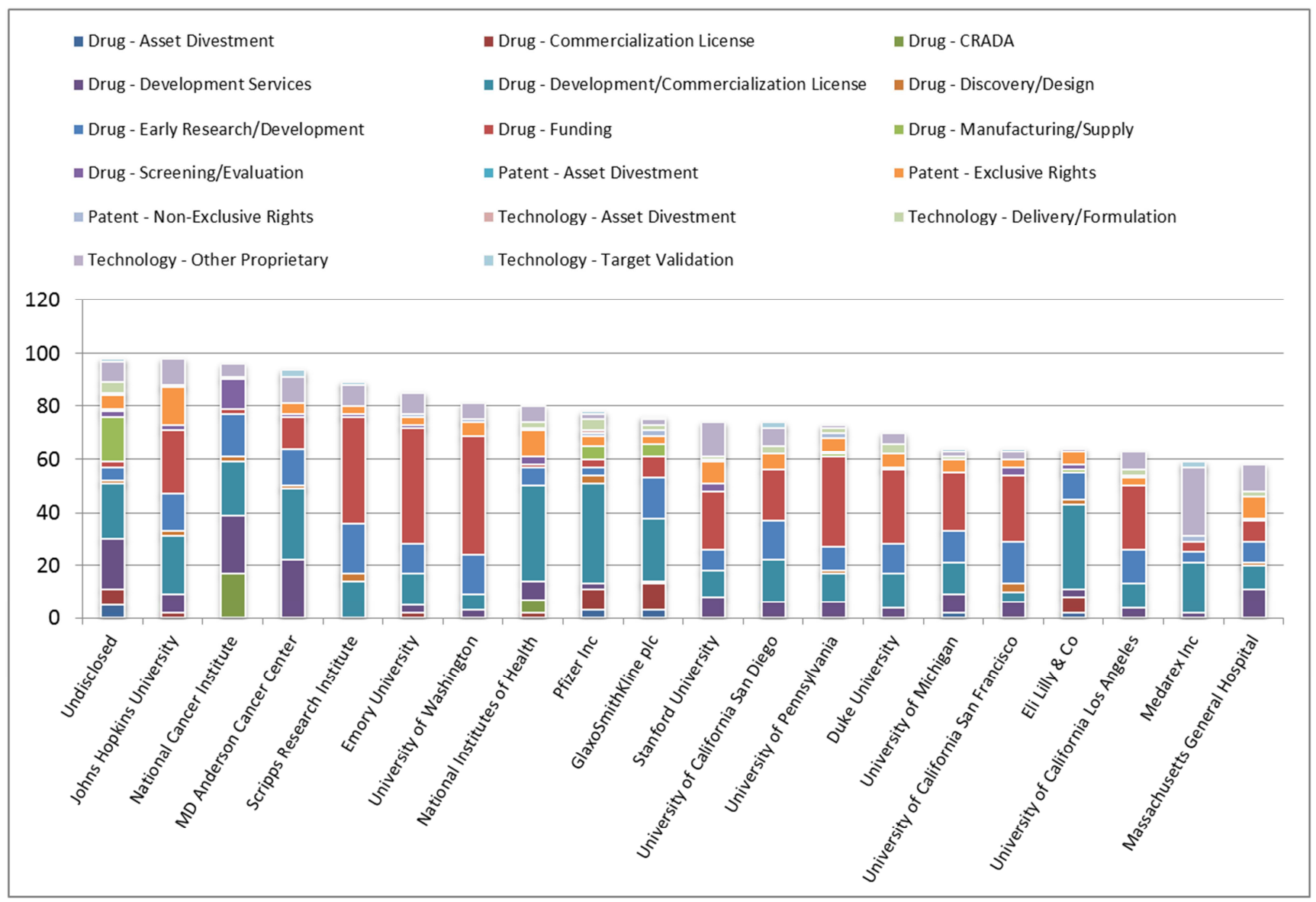

Figure 7. Detail of the number and deals of top 20 licensors.

On the other hand, the STTR program promotes science and technology innovation which SMEs collaborate with laboratories. It also promotes technology transfer between SMEs and laboratories. Like the SBIR program, it has 3 steps in order to implement its programs. The purpose for each phase is the same as SBIR, but the years of Phase I and the amount of funds are different. In phase I, it affords 150,000 dollars for about one year. Both of these programs fund to SMEs' R\&Ds, which have high possibility to be marketed, and have been started by the Small and Medium Business Administration since 2000. Currently 11 ministries (Ministry of Agriculture, Department of Commerce, Department of Defense, Ministry of Education, Department of Energy, Department of Homeland Security, Ministry of Transportation, Department of Health and Human Services, Ministry of Health and Human Services, Environment Agency, Aerospace Department, and National Science Foundation) are participating in the programs. Among them, 1.6 billion dollars are funded by National Institutes of Health, which is about $40 \%$ of the total [15].

Using the Cortellis database, this study analyzed whether the SBIR/STTR programs have been utilized by companies, universities and 1,195 organizations, which have drug pipelines, based in the U.S. This study has downloaded all the companies that have received the SBIR/STTR programs since 1983 by the information of http://sbir.gov. The study has collated these companies's information into the Cortellis database. As a result, 667 institutions, about 55.8\% of Cortellis database were found to have utilized SBIR/STTR programs in the past. Table 5 shows the top 10, among companies having drug pipelines, in the Cortellis database that utilized the SBIR/STTR programs.

Table 5. The top 10, among companies having drug pipelines, which utilized the SBIR/STTR programs.

\begin{tabular}{lll}
\hline Order & Company Name & Number \\
\hline 8 & Amgen Inc & 138 \\
10 & Omeros Corp & 109 \\
22 & Immunomedics Inc & 70 \\
31 & Chiron Corp & 57 \\
32 & ImClone Systems Inc & 55 \\
35 & Gilead Sciences Inc & 49 \\
39 & Medarex Inc & 45 \\
41 & Exelixis Inc & 44 \\
65 & IDEC Pharmaceuticals Corp & 29 \\
65 & Immunex Corp & 29 \\
\hline
\end{tabular}

Amgen Inc., ranked as the $1 \mathrm{st}$, is a biotechnology company founded in 1980. It utilized the SBIR/STTR system, after that, its sales have made a breakthrough to the world ranking number 13 . Within the top 10 companies, having drug pipelines, based in the U.S., Amgen Inc. is a company that 
have rapidly grown from a SME to a world-class biotechnology company in 35 years, while most of top 10 companies are major companies, like Pfizer Inc., Merck \& Co. Inc., Eli Lilly \& Co., Bristol Myers Squibb Co.

In Phase III of the SBIR/STTR programs, introduction to venture capital is implemented, and there is no doubt that venture capital is an important source of funding for growth of start-ups based on a new technology [16]. However, investment in start-ups by Japanese venture capital is one tenth of that in the United States [17].
Figure 8 shows annual investment amount and number of companies invested by Japanese venture capital, adding to OECD's Science, Technology and Industry Scoreboard 2013. As for the annual investment in Japan, it is converted and plotted on the basis that 1 dollar equals 100 yen. As can be seen from Figure 8, investment by venture capital is small and its activation is an important issue in Japan. In the United States, it can be seen that venture capitals have invested many start-ups and supported their prosperity.

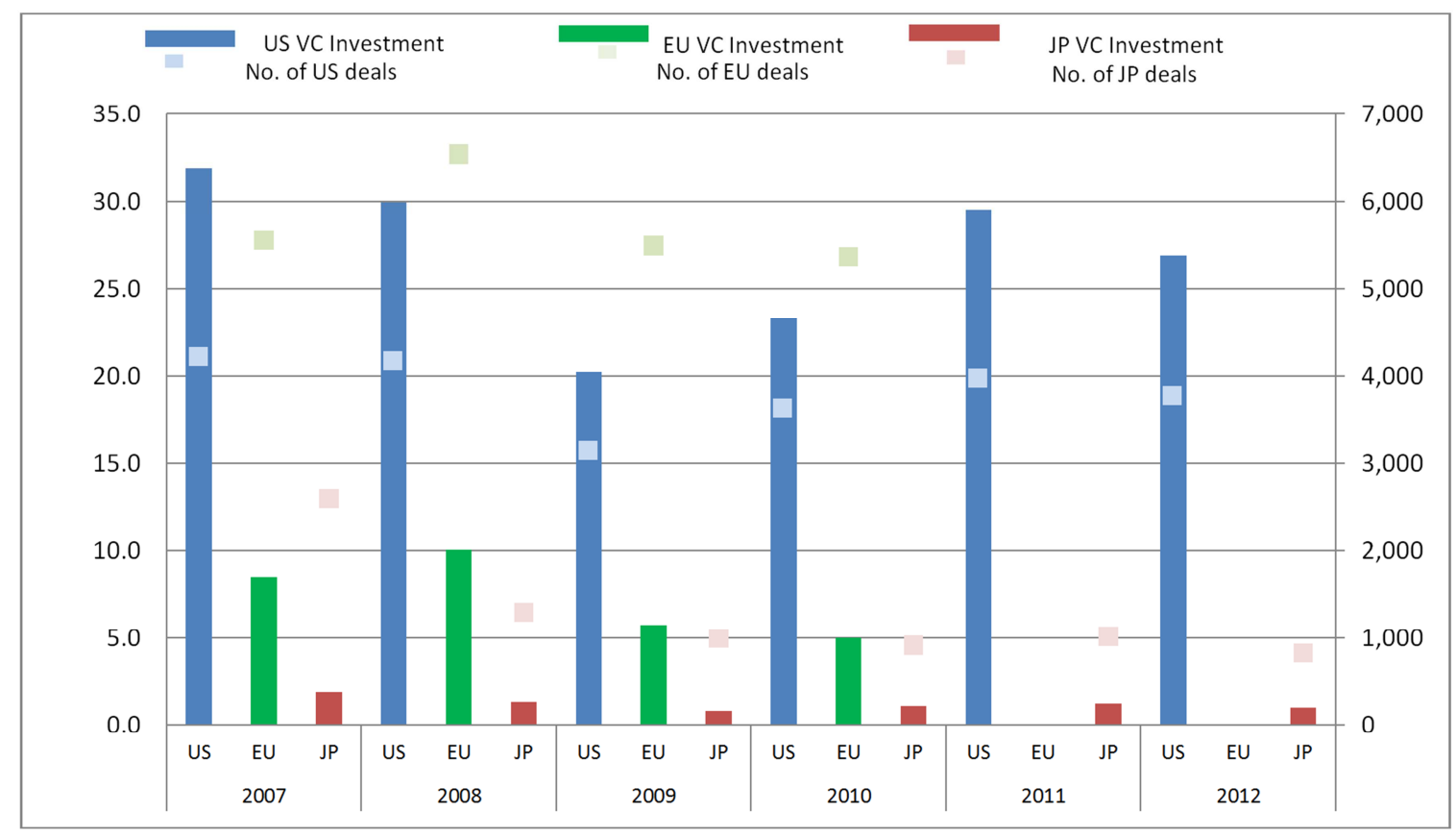

Figure 8. Annual investment amount and number of companies invested by JP, US, and EP venture capitals.

In AMED (Japanese version of NIH), it seems necessary to introduce the funding programs, including phase system like SBIR/STTR, for commercialization of drug pipelines of SMEs. It is also necessary to bridge government procurements and venture capital in Japan.

\section{Conclusion}

As a result of analyzing what kind of research grants from the government, foundation and companies in the U.S. are doing research funding for drug development, this study showed the following items.

Major companies, SMEs are dealing not only with other SMEs but also dealing actively with government agencies and foundations. Government involvement is one of the most important aspects, because it provides innovation system structure to link each entity. The foundation also plays the important role as a funding partner in U.S. It seems to relate the tax system of the country. Focusing the role of SMEs in U.S., there are some transactions that SMEs buy the candidates of major companies on the discovery phase. According to the Cortellis, about $55.8 \%$ of the companies developing drugs got grants of SBIR/STTR system. In the Phase III of SBIR/STTR system, it is available to get introductory service of venture capital. It is very important source of funds for start-ups and venture capital firms. Investment from venture capital firms in Japan is one tenth of that in US. In AMED, introductory service of venture capital, commercialization, and government procurement will become useful system.

NOTE: Japan Agency for Medical Research and Development (AMED), established in April 1, 2015. Cabinet Japan approved establishment of 'control tower' function for medical R\&D, in line with "Japan Revitalization Strategy" policy strategy in 2013. The Cabinet also approved the bills for Act on Promotion of Healthcare Policy and Act on the Independent Administrative Agency of Japan Agency for Medical Research and Development. The purpose of AMED is to promote integrated research and development in the field of medicine, from basic research to clinical trials.

\section{References}

[1] Lukach, Ruslan and Joseph Plasmans. 2002. "Measuring knowledge spillovers using patent citations: evidence from the Belgian firm's data" CESifo Working Paper NO.754 Category 9: Industrial organization. 
[2] Squicciarni, Mariagrazia, Helene Dernis and Chiara Criscuolo. 2013. "Measuring Patent Quality: Indicators of Technological and Economic Value" OECD/DSTI/DOC 3

[3] OECD. 2013. OECD Science, Technology and Industry Scoreboard 2013: Innovation for Growth. Paris, France: OECD Publishing

[4] Booth, Bruce, and Rodney Zemmel. 2004. "Prospects for Productivity." Nature Reviews Drug Discovery 3, 451-456

[5] Yoshiyuki OSABE, Mari JIBU. Development of new indicators for the launch of a Japanese version of the NIH (1): An overview and future prospects of pharmaceutical industry based on new indicators. Journal of Information Processing and Management. 2013, Vol. 56, No. 7, p. 448. https://www.jstage.jst.go.jp/article/johokanri/56/7/56_448/_art icle/-char/en

[6] Yoshiyuki OSABE, Mari JIBU. Development of new indicators for the launch of a Japanese version of the NIH (2): A technology-specific overview and future prospects of pharmaceutical industry. Journal of Information Processing and Management. 2013, Vol. 56, No. 9, p. 611. https://www.jstage.jst.go.jp/article/johokanri/56/9/56_611/_art icle/-char/en

[7] Yoshiyuki OSABE, Mari JIBU. Development of new indicators for the launch of a Japanese version of the NIH (3): Analysis of entities conducting pharmaceutical R\&D activities. Journal of Information Processing and Management. 2014, Vol. 56, No. 10, p. 685.

https://www.jstage.jst.go.jp/article/johokanri/56/10/56_685/_a rticle/-char/en

[8] Mari JIBU, Yoshiyuki OSABE. Development of new indicators for the launch of a Japanese version of the NIH (4): Refined indicators for patents linked with marketed drugs and pipelines. Journal of Information Processing and Management. 2014, Vol. 57, No. 1, p. 29.

https://www.jstage.jst.go.jp/article/johokanri/57/1/57_29/_arti cle/-char/en

[9] Mari JIBU, Yoshiyuki OSABE. Development of new indicators for the launch of a Japanese version of the NIH (5): Analysis based on refined indicators for patents linked with marketed drugs and pipelines. Journal of Information Processing and Management. 2014, Vol.57, No.3, p.178. https://www.jstage.jst.go.jp/article/johokanri/57/3/57_178/_art icle/-char/en

[10] Yoshiyuki OSABE, Mari JIBU. Development of new indicators for the launch of AMED (6): A disease-specific overview and future prospects of pharmaceutical industry. Journal of Information Processing and Management. 2014, Vol. 57, No. 5, p. 323. https://www.jstage.jst.go.jp/article/johokanri/57/5/57_323/_art icle/-char/en

[11] Mari JIBU, Yoshiyuki OSABE. Development of new indicators for the launch of AMED (8): Knowledge flows of the pharmaceutical innovation system. Journal of Information Processing and Management. 2014, Vol.57, No.8, p.562. https://www.jstage.jst.go.jp/article/johokanri/57/8/57 562/ art icle/-char/en

[12] Odagiri Hiroyuki. "Corporate Boundaries" in Pharmaceutical Research and Development, Pharmaceutical Industry Organization Theory, The University of Tokyo Press, 2002, p. $117-151$.

[13] Foundation Center. http://www.foundationcenter.org/findfunders/topfunders/top 10 0giving.html, (accessed 2018-09-06).

[14] Ministry of Finance. Points of budget for science and technology in FY2014, 2013, http://www.mof.go.jp/budget/budger_workflow/budget/fy201 4/seifuan26/05-07.pdf, (accessed 2018-09-06).

[15] SBIB/STTR. http://sbir.gov/, (accessed 2018-09-06).

[16] OECD Science, Technology and Industry Scoreboard 2013. http://www.oecd-ilibrary.org/science-and-technology/oecd-sci ence-technology-and-industry-scoreboard-2013_sti_scoreboar d-2013-en, (accessed 2018-09-06).

[17] Venture Enterprise Center. Survey result of venture capital investment trend in FY 2013 (preliminary report). http://www.vec.or.jp/wordpress/wp-content/files/2013-sokuho 20131018.pdf, (accessed 2018-09-06). 